\title{
Púrpura trombocitopénica trombótica sin esquistocitos
}

\author{
Thrombotic thrombocytopenic purpura without schistocytes
}

\section{Sr. Editor:}

En el hospital atendimos a una paciente con Púrpura trombótica trombocitopénica con un frotis de sangre periférica (FSP) que no mostraba esquistocitos. Se trataba de una mujer de 24 años sin antecedentes de importancia, hospitalizada por 5 días por presentar púrpura; no tenía fiebre ni hemorragias macroscópicas. Al examen físico tenía palidez moderada, petequias y equimosis en piel y mucosas. Estaba hemodinámicamente estable y no había visceromegalias, adenopatías ni alteraciones neurológicas.

Al ingreso tenía hemoglobina $(\mathrm{Hb}) \quad 6,9 \mathrm{gr} /$ dl y plaquetas de $13000 / \mathrm{mm}^{3}$, con constantes corpusculares, leucocitos, pruebas de función renal y de coagulación normales. En el FSP inicial había anisocitosis $2+$, poiquilocitosis $2+$ y policromatofilia $1+$, pero no se encontraron esquistocitos; reticulocitos $18 \%$, lactato deshidrogenasa (DHL) muy elevada, hiperbilirrubinemia indirecta leve. La serología para Hepatitis B y C, VIH y anticuerpos antinucleares fueron negativos. Fue evaluada por el Servicio de Hematología siendo catalogada como Síndrome de Evans e inició terapia con pulsos de Metilprednisolona 1 gr EV por día y ácido fólico $1 \mathrm{mg} /$ día VO. La evolución de la paciente fue estacionaria, sin fiebre ni otras molestias. No recibió transfusiones.

Al tercer día de tratamiento tuvo controles de $\mathrm{Hb}$ : $6,4 \mathrm{gr} / \mathrm{dl}$, plaquetas $16000 / \mathrm{mm}^{3}$, y test de Coombs directo negativo. Se hizo un segundo FSP que mostró macrocitosis $1+$, anisocitosis $2+$, hipocromía $2+$, policromatofilia $1+\mathrm{y}$ normoblastos $1+$, nuevamente no se evidenciaron esquistocitos. La paciente continuaba asintomática, pero se prolongó la terapia con metilprednisolona $\mathrm{EV}$, por dos días más.

Al quinto día de hospitalización, la paciente despertó con agitación psicomotriz, náuseas, vómitos y trastorno de conciencia con tendencia a la somnolencia. Al examen neurológico presentaba movimientos alternantes de decorticación y descerebración con signo de Babinski bilateral espontáneo presente. Se realizó nuevo frotis de sangre periférica y se inició manejo de vía aérea, sedoanalgesia y se transfunde 4 unidades de plasma fresco congelado, una unidad de paquete de glóbulos rojos y nueve unidades de plaquetas. El tercer FSP mostró macrocitosis 1+, policromatofilia $1+$, normoblastos $2+$, y esquistocitos $2+$ con plaquetas ausentes. La paciente falleció 5 horas después, mientras se realizaba el trámite para la plasmaféresis.

La púrpura trombocitopénica trombótica (PTT), que forma parte de las microangiopatías trombóticas (MAT), se caracteriza por anemia hemolítica microangiopática (esquistocitos en sangre periférica), trombocitopenia variable y elevación de reticulocitos y DHL(1)y es considerada una emergencia hematológica. Es una entidad rara, pero de una mortalidad mayor al 90\% si el paciente afectado no recibe el tratamiento con plasmaféresis $(1,2)$ de manera oportuna, pero para ello se necesita un diagnóstico temprano.

El problema ocurre cuando no se encuentra el componente básico de la MAT, los esquistocitos, para

\footnotetext{
Hospital Nacional Arzobispo Loayza.

Facultad de Medicina. Universidad Peruana Cayetano Heredia.

Médico Internista.

Profesor Auxiliar.
} 
hacer el diagnóstico (falso negativo). Existen otros reportes que mencionan casos de MAT sin detección de esquistocitos en el FSP, probablemente por un bajo grado de hemólisis en el momento de tomar la muestra $(3,4,5)$. Hasta ese momento no había consensos publicados sobre lo que es un esquistocito, por lo que podía haber inconsistencia en su identificación como variabilidad en el método de cuenta de esquistocitos, diferentes áreas de muestra evaluadas, o diferentes números de glóbulos rojos contados (6). Esto motivó la pregunta ¿podríamos haber realizado el diagnóstico de forma oportuna en esta paciente?

Si el caso hubiera sido un síndrome de Evans (anemia hemolítica autoinmune y trombocitopenia) la paciente hubiera tenido Test de Coombs positivo. Quizás por ello, Rock (7) propuso que "la PTT debe ser redefinida como un síndrome de anemia hemolítica microangiopática Coombs negativa y trombocitopenia en la ausencia de otras causas posibles de estas manifestaciones". Ello debió alertar a todos los médicos tratantes a buscar otras causas del cuadro y solicitar varios frotis de sangre periférica adicionales buscando esquistocitos (como salió en el tercer FSP). Mientras tanto, se pudo haber instaurado un tratamiento con plasmaféresis buscando la mejoría de la paciente, tal como reportan Fava y Caruana (8), en su paciente con cuadro similar igual sin esquistocitos y que tuvo buena respuesta al recambio plasmático.

Aunque en la actualidad ya existen documentos de consenso publicados por la International Council for Standardization in Haematology (ICSH) para la identificación y cuantificación de esquistocitos (6) y métodos automatizados para el análisis de esquistocitos (9) que deben seguirse en todos los laboratorios de hematología, nosotros sugerimos que si un paciente tiene anemia hemolítica con trombocitopenia sin esquistocitos en un solo frotis de sangre periférica y con test de Coombs directo negativo, debe manejarse como PTT con terapia con plasmaféresis, mientras se solicitan adicionales lecturas de otros frotis de sangre hasta encontrar esquistocitos o hasta ver la evolución del cuadro clínico durante los recambios plasmáticos, ya que el test de Coombs negativo alejaría la posibilidad de un Síndrome de Evans. Haciendo esto, se podría salvar la vida de un paciente con PTT, mientras se realiza el estudio diagnóstico del paciente.

\section{Otto Barnaby Guillén López 1,a; 2,b}

\section{Correspondencia:}

otto.guillen.1@upch.pe

\section{REFERENCIAS BIBLIOGRÁFICAS}

1. Contreras E y col. Guía diagnóstica y terapéutica de las microangiopatías trombóticas del Grupo Español de Aféresis. Med Clin (Barc). 2015; 144(7): 331.e1331.e13.

2. Scully M, Hunt BJ, Benjamin S, Liesner R, Rose P, Peyvandi F, Cheung B, Machin SJ. Guidelines on the diagnosis and management of thrombotic thrombocytopenic purpura and other thrombotic microangiopathies. British Journal of Haematology, 2012; 158:323-335.

3. Daram SR, Philipneri M, Puri N, Bastani B. Thrombotic thrombocytopenic purpura without schistocytes on the peripheral blood smear. South Med J. 2005 Mar; 98(3):392-395.

4. Brilliant SE, Lester PA, Ohno AK, Carlon MJ, Davis BJ, Cushner HM. Hemolytic-uremic syndrome without evidence of microangiopathic hemolytic anemia on peripheral blood smear. South Med J. 1996 Mar; 89(3):342-5.

5. Craig M. Thrombotic Thrombocytopenic Purpura: To Plex Without Schistiocytes? [abstract]. Journal of Hospital Medicine 2011; 6 (suppl 2). (citado el 28 de setiembre de 2017); Disponible en: http://www.shmabstracts.com/ abstract/thromboticthrombocytopenic-purpura-toplex-without-schistiocytes/

6. Zini G, D'onofrio G, Briggs C, Erber W, Jou JM, Lee SH, McFadden S, Vives-Corrons JL, Yutaka N, Lesesve JF. ICSH recommendations for identification, diagnostic value, and quantitation of schistocytes. Int J Lab Hematol. 2012; 34:107-116.

7. Rock GA. Management of thrombotic thrombocytopenic purpura. British Journal of Haematology. 2000; 109:496-507.

8. Fava S, Galizia AC. Thrombotic thrombocytopenic purpura-like syndrome in the absence of schistocytes. Br J Haematol. 1995 Mar; 89(3):643-644.

9. Hervent AS, Godefroid M, Cauwelier B, Billiet J, Emmerechts J. Evaluation of schistocyte analysis by a novel automated digital cell morphology application. Int J Lab Hematol. 2015; 37:588-596

Recibido: 20/07/2018 